\title{
Factors Associated with Community Awareness on COVID-19 in a Developing Country: Implications for Optimal Risk Communication
}

\author{
Huong Thi Le', Thao Thi Phuong Nguyen ${ }^{2,3}$, Corey Jacinto ${ }^{4}{ }^{4}$, Cuong Tat Nguyen ${ }^{2,3}$, Linh Gia Vu ${ }^{2,3}$, \\ Hien Thu Nguyen ${ }^{2,3}$, Minh Ngoc Le Vu ${ }^{5}$, Xuan Thi Thanh Le', Thao Thanh Nguyen', Quan Thi Pham', \\ Nhung Thi Kim Ta $\mathbb{D}^{\prime}$, Quynh Thi Nguyen', Carl A Latkin $\mathbb{D}^{6}$, Cyrus SH Ho $\mathbb{D}^{7,8}$, Roger CM Ho $\mathbb{D}^{7,9}$ \\ 'Institute for Preventive Medicine and Public Health, Hanoi Medical University, Hanoi, Vietnam; ${ }^{2}$ Institute for Global Health Innovations, Duy Tan \\ University, Da Nang, Vietnam; ${ }^{3}$ Faculty of Medicine, Duy Tan University, Da Nang, Vietnam; ${ }^{4}$ Department of Health Policy \& Management, University \\ of California, Los Angeles, CA, USA; ${ }^{5}$ nstitute of Health Economics and Technology, Hanoi, Vietnam; ${ }^{6}$ Bloomberg School of Public Health, Johns \\ Hopkins University, Baltimore, MD, USA; ${ }^{7}$ Department of Psychological Medicine, Yong Loo Lin School of Medicine, National University of Singapore, \\ Singapore; ${ }^{8}$ Department of Psychological Medicine, National University Health System, Singapore; ${ }^{9}$ Institute for Health Innovation and Technology \\ (iHealthtech), National University of Singapore, Singapore
}

Correspondence: Cuong Tat Nguyen, Duy Tan University, 254 Nguyen Van Linh Street, Da Nang, 550000, Vietnam, Tel +84 35 8705I77, Email nguyentatcuong@duytan.edu.vn

Purpose: New COVID-19 variants pose great challenges in protecting the success of vaccination programs. Awareness of community becomes an important component to prevent the spread of COVID-19. This study aims to analyze people's awareness of COVID-19 and identify the implications for optimal risk communication in Vietnam.

Study Methods and Materials: A total of 341 individuals participated in an online cross-sectional study. Community awareness on COVID-19 was examined by using a structured questionnaire. Multivariable Tobit regression was used to examine associated factors with community awareness.

Results: Our results indicated high levels of awareness of local COVID-19 situation, transmission risks, and preventive behavioral practices during the first week of social isolation. Higher awareness of local pandemic situation was associated with female respondents (Coef.: 6.19; 95\% CI: 0.51; 11.87) and larger family sizes of above 5 people (Coef.: 9.00; -1.00; 19.00). Respondents between 35-44 years old were shown to be less aware of preventive behavioral practices than other age groups, including the group of participants above 44 years old (Coef.: -0.34 ; 95\% CI: -0.67 ; -0.02). Lastly, participants who were "fairly satisfied" with information resources had awareness levels of preventive behavioral practices lower than that of "unsatisfied" respondents (Coef.: $-0.45 ; 95 \%$ CI: $0.74 ;-0.16)$.

Conclusion: This study offers crucial insights into the pandemic awareness of citizens and risk communication effectiveness during COVID-19 in Vietnam. The study findings shall serve the development of policies and interventions aimed at empowering individuals in the local and global fight against coronavirus.

Keywords: COVID-19 epidemic, risk communication, awareness generation, preventive measures, Vietnam

\section{Introduction}

The novel coronavirus disease (COVID-19) emerged as global Health concern due to its hazard and rapid geographic spread. ${ }^{1}$ The impacts of COVID-19 have been posing numerous negative consequences, such as global health crisis, social behavior changes, economic shock, and challenges at the national level. ${ }^{2-5}$ In late December 2019, Chinese authorities reported the first case of COVID-19 in Wuhan city of Hubei Province, China. ${ }^{6}$ The spread of COVID-19 rapidly progressed to many countries and increased exponentially. ${ }^{7}$ In response to the nascent pandemic, the World Health Organization (WHO) declared COVID-19 as a Public health emergency of international concern on January 30, $2020 .^{8}$ 
Patients with COVID-19 might suffer a variety of respiratory tract infections from mild cold to severe respiratory distress syndrome. ${ }^{1,9}$ Therefore, the cornerstones of disease containment are early diagnosis, effective treatment, and preventive measures. ${ }^{10}$ COVID-19 vaccines were expected to put an end to the current pandemic situation with the efforts of scientists and pharmacy manufacturers for 12 billion vaccine doses in 2021, but vaccine inequality occurred with most of the available vaccines being sent to rich countries - as of 7 May 2021. ${ }^{11,12}$ Furthermore, hesitancy and resistance issues in COVID-19 vaccination provide significant setbacks in reaching community immunity. ${ }^{13}$ Simultaneously, the appearance of COVID-19 variants posed new, challenging threats for all nations. There had been a calculated possibility that new variants could escape the immune response of the human body, and thus reduce the current vaccine effectiveness. ${ }^{14}$ Therefore, traditional practices such as social distancing, contact tracing, wearing facemask, handwashing, closing educational institutions, and prioritizing digital solutions had once again become key protective measures against the transmission of COVID-19, while proactive communication of COVID-19 risks may improve public awareness and preventive preparedness. ${ }^{15-18}$

In Vietnam, the government announced a nationwide outbreak of COVID-19 and Instituted a 14-day national lockdown on April 1, 2020. ${ }^{19}$ As of 7 April, Vietnam recorded 241 confirmed cases and no fatality, of which approximately $60 \%$ recently returned from abroad. ${ }^{20,21}$ The country has kept the spread of COVID-19 at a relatively slow rate before Delta variants appeared in August 2021. In efforts to limit contagion, the Vietnamese government called for increasing awareness and selfprotective behaviors, including mandatory masks use, hand-washing routine, and immediate medical care for symptomatic patients. ${ }^{22}$ Effective communication between the authorities and citizens, including communication strategies to educate, inform, and empower communities with correct information about COVID-19, had resulted in successful prevention of the epidemic. ${ }^{23,24}$ However, to this day, Vietnam is still undergoing large changes in morphology and transmission, one of which is the appearance of new variants. Novel variants of the SARS-CoV-2 virus and growing clusters of cases in different provinces/regions had forced the government to make adjustments in COVID-19 prevention strategies and policies. ${ }^{25-27}$

Prompt and proactive responses are hence extremely crucial in the development of strategies and policies for the next stages. ${ }^{28}$ Previous COVID-19 studies published by Vietnamese authors mainly discussed outcomes derived from summary, review, and reassessment of COVID-19 response policies and strategies and served merely as commentaries without specific evidence. $^{29-32}$ This study aims to analyze residents' awareness of COVID-19 including local epidemic situations, disease transmission, and preventive behavioral practices. Our work also focuses on identifying implications for optimal risk communication during the first nationwide lockdown in Vietnam. The results can provide valuable resources to improve policies and preventive strategies for future outbreaks.

\section{Materials and Methods}

\section{Study Design, Sampling Method, and Data Collection}

This online cross-sectional study used individual-level data collected during the first week of the government-mandated nationwide lockdown from April 1st to April 7th, 2020. The eligibility criteria included: (1) agreeing to take part in the research via online informed consent; (2) possessing the ability to access the online questionnaire; (3) having the capability to read and respond to the questionnaire.

A core group of Hanoi Medical University affiliates was established at the beginning of the recruitment process. Our team took advantage of the medical professional network of members to attract participants and encouraged individuals to share the survey invitation link on social platforms ie Facebook and Zalo. A total of 341 individuals participated in the study during the one-week data collection period.

\section{Measurement and Data Collection Tool}

In this study, we used the SurveyMonkey platform to collect data through an online questionnaire (surveymonkey.com). ${ }^{33}$ This online survey platform allows the researcher to know the IP address of each respondent. By combining IP addresses with other information such as demographic characteristics, we could control the duplication issue by identifying which data were similar and then removing the duplication. We also had the screen questions at the beginning to ensure that the participants met the inclusion criteria before taking part in the survey. This method provides efficiencies such as conserving time, lowering costs, and 
reaching a large number of samples. A structured questionnaire including five major components: 1) Demographic characteristics; 2) COVID-19 information sources; 3) COVID-19 information satisfaction; 4) Awareness of local COVID-19 situation; 5) Awareness of transmission risks; 6) Awareness of preventive behavioral practices. Research information and informed consent were introduced at the beginning of the study. Participants answered the questionnaire after agreeing to join the survey.

\section{Outcome Variables}

The outcome variables included 3 domains related to respondents' awareness of the COVID-19 situation in their respective localities, transmission risks, and preventive behavioral practices. ${ }^{34}$

Awareness of local COVID-19 situation (3 questions) included number of cases, recoveries, and deaths.

Awareness of COVID-19 transmission mechanisms (3 questions) consisted droplet transmission, contaminated surfaces, and airborne transmission.

Awareness of transmission prevention practices (7 questions) included: "washing hands with soap", "wearing a mask when going out of one's private residence", "covering coughs and sneezes", "minimizing going outside of one's residence", "avoiding sharing personal items", "washing hands after handling exposed objects and surfaces", and "washing hands immediately after coughing, sneezing or rubbing eyes".

Each item had five response levels: 1=Totally disagree, 2=Disagree; $3=$ Neutral; $4=$ Agree, and $5=$ Totally agree. Option 4 and option 5 were equivalent to 1 point, and others to 0 point. Total scores of each domain (range of 0 to 10) were calculated as: total score divided by total number of questions and multiplied by 10 . Higher scores indicated greater degrees of awareness adequacy.

\section{Covariables}

Demographic characteristics: Respondents were asked a number of questions including gender (male/female); region of residents (Northern/Central/South/Foreign); age groups (under 25/25-34/35-44/above 44); religion (yes/no); marital status (single/living with spouse/others); occupation (Health workers/professional educators/white collar workers/ students/others); occupation status (public employment contract/ permanent employment contract/ fixed-term fulltime contract/ no contract/ others); number of children; number of children older than 15 .

COVID-19 Information sources: Respondents also reported the average of hours per day spent on searching, their sources of COVID-19 information (including social networks, internet, television, radio, newspaper, relatives, friends/colleagues).

Satisfaction of COVID-19 information sources including unsatisfied, fairly satisfied, or very satisfied.

\section{Data Analysis}

Collected data were analyzed using STATA version 15.0. The sample population's characteristics were examined by descriptive statistics and then appropriately presented as frequencies, percentages, means, and standard deviations. Statistical differences in demographic summary statistics, information sources, hours spent per day searching for information, satisfaction with educational attainment, awareness of local COVID-19 situation, transmission risks, and preventive behavioral practices were derived using analysis of variance (ANOVA) and Pearson's Chi-square test.

Factors associated with band scores of awareness of the local COVID-19 situation were "Awareness of local COVID19 situation", "Awareness of COVID-19 transmission mechanisms", and "Awareness of transmission prevention practices". A multivariable Tobit regression model was applied to determine factors related to Vietnamese awareness through independent variables (including demographic characteristics, COVID-19 information sources, and satisfaction). Our dependent variable was censored in the range of $0-10$, therefore a multivariable Tobit regression was a fit model for the study. Moreover, the final regression model was developed based on the forward stepwise strategy with a p-value threshold of less than 0.2. Statistical significance was defined at a p-value of less than 0.05 .

\section{Results}

\section{Demographic Characteristics of Respondents}

The demographic characteristics of survey respondents were displayed in Table 1. The average age of respondents was 33.7 years $(\mathrm{SD}=10.8)$, the average number of children per person was $1.1(\mathrm{SD}=1.0)$, and the average number of 
Table I Demographic Characteristics of Respondents

\begin{tabular}{|c|c|c|c|c|c|c|c|c|c|}
\hline \multirow[t]{2}{*}{ Characteristics } & \multicolumn{2}{|c|}{ High School and Below } & \multicolumn{2}{|c|}{ Undergraduate } & \multicolumn{2}{|c|}{ Graduate Degree } & \multicolumn{2}{|c|}{ Total } & \multirow[t]{2}{*}{ p-value } \\
\hline & $\mathbf{n}$ & $\%$ & $\mathbf{n}$ & $\%$ & $\mathbf{n}$ & $\%$ & $\mathbf{n}$ & $\%$ & \\
\hline Total & 75 & 22 & 184 & 54 & 82 & 24.1 & 341 & 100 & \\
\hline Gender & & & & & & & & & 0.20 \\
\hline Male & 20 & 26.7 & 64 & 34.8 & 33 & 40.2 & 117 & 34.3 & \\
\hline Female & 55 & 73.3 & 120 & 65.2 & 49 & 59.8 & 224 & 65.7 & \\
\hline Region & & & & & & & & & $<0.01$ \\
\hline Northern & 52 & 69.3 & 145 & 78.8 & 65 & 79.3 & 262 & 76.8 & \\
\hline Central & 19 & 25.3 & 13 & 7.1 & 8 & 9.8 & 40 & 11.7 & \\
\hline South & 4 & 5.3 & 23 & 12.5 & 7 & 8.5 & 34 & 10 & \\
\hline Foreign & 0 & 0 & 3 & 1.6 & 2 & 2.4 & 5 & 1.5 & \\
\hline Age group & & & & & & & & & $<0.01$ \\
\hline Under 25 & 62 & 82.7 & 23 & 12.5 & 0 & 0 & 85 & 24.9 & \\
\hline $25-34$ & 5 & 6.7 & 78 & 42.4 & 19 & 23.2 & 102 & 29.9 & \\
\hline $35-44$ & 2 & 2.7 & 56 & 30.4 & 36 & 43.9 & 94 & 27.6 & \\
\hline Above 44 & 6 & 8 & 27 & 14.7 & 27 & 32.9 & 60 & 17.6 & \\
\hline Religion & & & & & & & & & 0.36 \\
\hline Yes & 10 & 13.3 & 32 & 17.4 & 9 & 11 & 51 & 15 & \\
\hline No & 65 & 86.7 & 152 & 82.6 & 73 & 89 & 290 & 85 & \\
\hline Marital status & & & & & & & & & $<0.01$ \\
\hline Single & 65 & 86.7 & 52 & 28.3 & 10 & 12.2 & 127 & 37.2 & \\
\hline Living with spouse & 9 & 12 & 128 & 69.6 & 69 & 84.2 & 206 & 60.4 & \\
\hline Others & 1 & 1.3 & 4 & 2.2 & 3 & 3.7 & 8 & 2.4 & \\
\hline Family size & & & & & & & & & 0.36 \\
\hline I-2 people & 20 & 26.7 & 32 & 17.4 & 12 & 14.6 & 64 & 18.8 & \\
\hline 3-5 people & 48 & 64 & 133 & 72.3 & 60 & 73.2 & 241 & 70.7 & \\
\hline Above 5 people & 7 & 9.3 & 19 & 10.3 & 10 & 12.2 & 36 & 10.6 & \\
\hline Occupation & & & & & & & & & $<0.01$ \\
\hline Health workers & 1 & 1.3 & 45 & 24.5 & 20 & 24.4 & 66 & 19.4 & \\
\hline Professional educators & I & 1.3 & 30 & 16.3 & 25 & 30.5 & 56 & 16.4 & \\
\hline White collar workers & 1 & 1.3 & 50 & 27.2 & 20 & 24.4 & 71 & 20.8 & \\
\hline Students & 64 & 85.3 & 20 & 10.9 & 0 & 0 & 84 & 24.6 & \\
\hline Others & 8 & 10.7 & 39 & 21.2 & 17 & 20.7 & 64 & 18.8 & \\
\hline Occupation status & & & & & & & & & $<0.01$ \\
\hline Public employment contract ${ }^{a}$ & 2 & 2.7 & 65 & 35.3 & 47 & 57.3 & 114 & 33.4 & \\
\hline Permanent employment contract & 2 & 2.7 & 48 & 26.1 & 16 & 19.5 & 66 & 19.4 & \\
\hline Fixed-term fulltime contract ${ }^{b}$ & 1 & 1.3 & 22 & 12 & 11 & 13.4 & 34 & 10 & \\
\hline No contract ${ }^{c}$ & 67 & 89.3 & 34 & 18.5 & 3 & 3.7 & 104 & 30.5 & \\
\hline \multirow[t]{2}{*}{ Others } & 3 & 4 & 15 & 8.2 & 5 & 6.1 & 23 & 6.7 & \\
\hline & Mean & SD & Mean & SD & Mean & SD & Mean & SD & p-value \\
\hline Number of children & 0.4 & 0.9 & 1.2 & $\mathrm{I}$ & 1.7 & 0.8 & I.I & I & $<0.01$ \\
\hline Number of children older than I5 & 0.2 & 0.6 & 0.3 & 0.6 & 0.5 & 0.8 & 0.3 & 0.7 & $<0.01$ \\
\hline Age & 24.4 & 9.8 & 34.1 & 9.2 & 41.1 & 8.5 & 33.7 & 10.8 & $<0.01$ \\
\hline
\end{tabular}

Notes: ${ }^{\text {P}}$ Public employment contract: type of contract for people working in public non-business units under working contracts and salaried from salary funds of public nonbusiness units in accordance with law. ${ }^{b}$ Fixed-term full-time contract is a contractual relationship between an employee and an employer that lasts for a specified period. In Vietnam, there are two kinds of fixed-term contracts include the definite term contract of $12-36$ months and the seasonal or fixed-term contract of $<12$ months. ${ }^{c}$ No contract: farmers/students/homemakers/ unemployed/retired.

children older than 15 was 0.3 ( $\mathrm{SD}=0.7$ ). The majority of respondents were female $(67.5 \%)$, resided in Northern Vietnam (76.8\%), cited no religious affiliation (85.0\%), resided with their spouse $(60.0 \%)$, had a family of 3-5 people (70.7\%), and attained a bachelor's degree (54.0\%). Students $(24.6 \%)$ comprised the largest proportion of the sample, followed by white-collar workers $(20.8 \%)$, health workers $(19.4 \%)$, others $(18.8 \%)$, and professional educators $(16.4 \%)$. 


\section{COVID-19 Information Sources and Satisfaction}

Table 2 indicated the Internet (82.4\%) as the most common source of health information about COVID-19 for the entire sample, while the least common source was radio (12.9\%). The most popular source of information among those with a high School degree or less was social networks (84.0\%), while those with a graduate degree used the Internet most frequently $(89.0 \%)$, and those with a graduate degree used television most frequently $(75.6 \%)$. The majority of respondents (95.4\%) were very satisfied or fairly satisfied with available health information. Differences in satisfaction levels by education attainment were not statistically significant. The average time spent per day on searching for COVID-19 information was 1.8 hours $(\mathrm{SD}=2.0)$ with no statistically significant difference by education attainment.

\section{Awareness of Local COVID-19 Situation, Transmission Risks, and Preventive Behavioral Practices}

Table 3 showed measures of awareness of the COVID-19 situation in respondents' respective localities, transmission risks, and preventive behavioral practices. It also indicated the differences in these measures in correspondence with education attainment. The mean band scores of the three domains were 9.6 $(\mathrm{SD}=1.7), 8.4(\mathrm{SD}=1.7)$, and $8.6(\mathrm{SD}=1.1)$, respectively. Differences in the band scores of all three domains by education attainment were not statistically significant.

The study sample indicated high awareness of the local COVID-19 situation. According to their responses, $97.1 \%$ had adequate awareness of the number of cases, $95 \%$ had adequate awareness of the number of recoveries, and $94.7 \%$ had adequate awareness of the number of deaths. Differences of all three metrics of awareness of the local COVID-19 situation across education attainment groups were not statistically significant.

Regarding the domain of adequate awareness about COVID-19 transmission mechanisms, participants possessed good awareness concerning droplet transmission (99.4\%) and contaminated surfaces (98.8\%). Adequate awareness of airborne transmission was considerably lower within the study population $(54.8 \%)$. Those with a high school degree or less had the lowest rate of adequate awareness of airborne transmission $(45.3 \%)$. The education attainment group's differences were only statistically significant for adequate awareness of contaminated surfaces, in which respondents possessing a high school degree or less had the lowest percentage $(96.0 \%)$.

Table 2 COVID-19 Information Sources and Satisfaction

\begin{tabular}{|c|c|c|c|c|c|c|c|c|c|}
\hline \multirow[t]{2}{*}{ Characteristics } & \multicolumn{2}{|c|}{$\begin{array}{c}\text { High } \\
\text { School and } \\
\text { Below }\end{array}$} & \multicolumn{2}{|c|}{ Undergraduate } & \multicolumn{2}{|c|}{$\begin{array}{c}\text { Graduate } \\
\text { Degree }\end{array}$} & \multicolumn{2}{|c|}{ Total } & \multirow[t]{2}{*}{ p-value } \\
\hline & $\mathbf{n}$ & $\%$ & $\mathbf{n}$ & $\%$ & $\mathbf{n}$ & $\%$ & $\mathbf{n}$ & $\%$ & \\
\hline Total & 75 & 22 & 184 & 54 & 82 & 24.1 & 341 & 100 & \\
\hline \multicolumn{10}{|l|}{ Satisfaction of information sources } \\
\hline Unsatisfied & 7 & 9.3 & 8 & 4.4 & I & 1.2 & 16 & 4.7 & 0.2 \\
\hline Fairly satisfied & 34 & 45.3 & 93 & 50.5 & 42 & 51.2 & 169 & 49.6 & \\
\hline Very satisfied & 34 & 45.3 & 83 & 45.1 & 39 & 47.6 & 156 & 45.8 & \\
\hline \multicolumn{10}{|l|}{ Information sources } \\
\hline Social network & 63 & 84 & |4| & 76.6 & 50 & 61 & 254 & 74.5 & $<0.01$ \\
\hline Internet & 55 & 73.3 & 153 & 83.2 & 73 & 89 & 281 & 82.4 & 0.03 \\
\hline Television & 55 & 73.3 & 139 & 75.5 & 62 & 75.6 & 256 & 75.1 & 0.93 \\
\hline Radio & 4 & 5.3 & 26 & 14.1 & 14 & 17.1 & 44 & 12.9 & 0.07 \\
\hline Newspaper & 15 & 20 & 58 & 31.5 & 29 & 35.4 & 102 & 29.9 & 0.09 \\
\hline Relatives & 22 & 29.3 & 66 & 35.9 & 27 & 32.9 & 115 & 33.7 & 0.59 \\
\hline \multirow[t]{2}{*}{ Friends/colleagues } & 29 & 38.7 & 92 & 50 & 50 & 61 & $|7|$ & 50.2 & 0.02 \\
\hline & Mean & SD & Mean & SD & Mean & SD & Mean & SD & p-value \\
\hline $\begin{array}{l}\text { Hours per day spent searching for COVID- } 19 \\
\text { information }\end{array}$ & 2 & 3 & 1.9 & 1.8 & 1.4 & 0.7 & 1.8 & 2 & 0.61 \\
\hline
\end{tabular}


Table 3 Awareness of the Local COVID-19 Situation, Transmission Risks and Preventive Behavioral Practices

\begin{tabular}{|c|c|c|c|c|c|c|c|c|c|}
\hline \multirow[t]{2}{*}{ Characteristics } & \multicolumn{2}{|c|}{$\begin{array}{l}\text { High } \\
\text { School } \\
\text { Degree or } \\
\text { Below }\end{array}$} & \multicolumn{2}{|c|}{ Undergraduate } & \multicolumn{2}{|c|}{$\begin{array}{l}\text { Graduate } \\
\text { Degree }\end{array}$} & \multicolumn{2}{|c|}{ Total } & \multirow[t]{2}{*}{ p-value } \\
\hline & $\mathbf{n}$ & $\%$ & $\mathbf{n}$ & $\%$ & $\mathbf{n}$ & $\%$ & $\mathbf{n}$ & $\%$ & \\
\hline \multicolumn{10}{|l|}{ Awareness of local COVID-19 situation } \\
\hline Number of cases & 73 & 97.3 & 178 & 96.7 & 80 & 97.6 & 331 & 97.1 & 0.92 \\
\hline Number of recoveries & 68 & 90.7 & 176 & 95.7 & 80 & 97.6 & 324 & 95 & 0.12 \\
\hline Number of deaths & 72 & 96 & 173 & 94 & 78 & 95.1 & 323 & 94.7 & 0.8 \\
\hline \multicolumn{10}{|l|}{ Awareness of COVID-19 transmission } \\
\hline Droplet transmission & 74 & 98.7 & 183 & 99.5 & 82 & 100 & 339 & 99.4 & 0.55 \\
\hline Contaminated surfaces & 72 & 96 & 183 & 99.5 & 82 & 100 & 337 & 98.8 & 0.03 \\
\hline Airborne transmission & 34 & 45.3 & 104 & 56.5 & 49 & 59.8 & 187 & 54.8 & 0.15 \\
\hline \multicolumn{10}{|l|}{ Awareness of preventive behavioral practices } \\
\hline Washing hands with soap & 73 & 97.3 & 182 & 98.9 & 81 & 98.8 & 336 & 98.5 & 0.62 \\
\hline Wearing a mask when going out & 75 & 100 & 178 & 96.7 & 82 & 100 & 335 & 98.2 & 0.07 \\
\hline Covering coughs and sneezes & 74 & 98.7 & 178 & 96.7 & 82 & 100 & 334 & 98 & 0.2 \\
\hline Minimize going out & 72 & 96 & 179 & 97.3 & 80 & 97.6 & 331 & 97.1 & 0.82 \\
\hline $\begin{array}{l}\text { Washing hands immediately after coughing, rubbing eyes, } \\
\text { sneezing }\end{array}$ & 61 & 81.3 & 153 & 83.2 & 63 & 76.8 & 277 & 81.2 & 0.48 \\
\hline Washing hands after handling exposed objects and surfaces & 54 & 72 & $15 \mid$ & 82.1 & 70 & 85.4 & 275 & 80.7 & 0.08 \\
\hline \multirow[t]{2}{*}{ Avoidance of sharing personal items } & 55 & 73.3 & 119 & 64.7 & 55 & 67.1 & 229 & 67.2 & 0.4 \\
\hline & Mean & SD & Mean & SD & Mean & SD & Mean & SD & p-value \\
\hline \multicolumn{10}{|l|}{ Total score (band score: $0-10$ ) } \\
\hline Awareness of local COVID-19 situation & 9.5 & 1.6 & 9.5 & 1.8 & 9.7 & 1.4 & 9.6 & 1.7 & 0.81 \\
\hline Awareness of COVID-19 transmission & 8 & 1.7 & 8.5 & 1.8 & 8.7 & 1.6 & 8.4 & 1.7 & 0.08 \\
\hline Awareness of preventive behavioral practices & 8.5 & 1 & 8.6 & 1.2 & 8.6 & 1.1 & 8.6 & 1.1 & 0.76 \\
\hline
\end{tabular}

The awareness of preventive behavioral practices domain indicated high levels of all items as the adequate awareness of "washing your hands with soap", "wearing a mask when going out" and "cover in your cough and sneeze" were rated $98.5 \%, 98.2 \%, 98.0 \%$, respectively, in which respondents attaining a graduate degree scored the highest. On the other hand, "washing hands immediately after coughing, rubbing eyes, sneezing" held a lower proportion of adequate awareness than other measures at $81.2 \%$.

\section{Factors Associated with Awareness of Local COVID-19 Situation, Transmission Risks, and Preventive Behavioral Practices}

Table 4 illustrated the associations between domains of COVID-19 awareness and independent variable groups (demographic characteristics, COVID-19 information sources, and satisfaction). Higher scores of awareness of the local COVID-19 situation were significantly associated with gender, family size, and occupation $(\mathrm{P}<0.05)$. Identifying as female was associated with higher levels of awareness of the local COVID-19 situation (Coef.: 6.19; 95\% CI: 0.51 ; 11.87). Family size of 3-5 people was associated with greater awareness of the local COVID-19 situation compared to family size of 1-2 people (Coef:: 7.57; 95\% CI: 1.22; 13.93). Professional educators reported a lower awareness of the local COVID-19 situation band score relative to health workers (Coef.: $-7.95 ; 95 \%$ CI: $-14.67 ;-1.23$ ).

Awareness of transmission mechanisms band score was significantly associated with educational attainment and using television as an information source. Holding an undergraduate degree (Coef.: 1.49; 95\% CI: 0.21; 2.76) and holding a graduate degree (Coef.: 2.54; 95\% CI: 0.95 ; 4.14) were associated with higher scores on awareness of COVID-19 
Table 4 Factors Associated with Awareness of Local COVID-19 Situation, Transmission Risks and Preventive Behavioral Practices

\begin{tabular}{|c|c|c|c|c|c|c|}
\hline \multirow[t]{2}{*}{ Band Score of Outcomes } & \multicolumn{2}{|c|}{$\begin{array}{l}\text { Awareness of COVID-I9 } \\
\text { Situation in the Locality }\end{array}$} & \multicolumn{2}{|c|}{$\begin{array}{l}\text { Awareness of COVID-19 } \\
\text { Transmission }\end{array}$} & \multicolumn{2}{|c|}{$\begin{array}{l}\text { Awareness of Preventive } \\
\text { Behavioral Practices }\end{array}$} \\
\hline & Coef. & $95 \% \mathrm{Cl}$ & Coef. & $95 \% \mathrm{Cl}$ & Coef. & $95 \% \mathrm{Cl}$ \\
\hline Gender (reference: male) & $6.19^{\mathrm{c}}$ & $0.5 \mathrm{I} ; 1 \mathrm{II} .87$ & $0.76^{\mathrm{b}}$ & $-0.12 ; 1.63$ & & \\
\hline \multicolumn{7}{|l|}{ Region (ref: Northern) } \\
\hline Central & $9.78^{b}$ & $-1.55 ; 21.11$ & & & & \\
\hline South & & & & & $0.49^{b}$ & $-0.00 ; 0.97$ \\
\hline Foreign & & & & & -0.97 & $-2.13 ; 0.19$ \\
\hline \multicolumn{7}{|l|}{ Age group (ref: under 25 ) } \\
\hline $35-44$ & & & & & $-0.34^{\mathrm{c}}$ & $-0.67 ;-0.02$ \\
\hline Above 44 & 8.92 & $-1.92 ; 19.77$ & -0.88 & $-2.02 ; 0.27$ & & \\
\hline Religious affiliation (ref: yes) & & & $1.08^{\mathrm{b}}$ & $-0.16 ; 2.31$ & & \\
\hline \multicolumn{7}{|l|}{ Family size (ref: I-2 people) } \\
\hline 3-5 people & $7.57^{\mathrm{c}}$ & $1.22 ; 13.93$ & & & & \\
\hline Above 5 people & $9.00^{\mathrm{b}}$ & $-1.00 ; 19.00$ & & & & \\
\hline \multicolumn{7}{|l|}{$\begin{array}{l}\text { Education level (ref: High school degree or } \\
\text { below) }\end{array}$} \\
\hline Undergraduate & & & $1.49^{\mathrm{c}}$ & $0.21 ; 2.76$ & & \\
\hline Graduate degree & & & $2.54^{\mathrm{a}}$ & $0.95 ; 4.14$ & & \\
\hline \multicolumn{7}{|l|}{ Occupation (ref: health workers) } \\
\hline Professional educators & $-7.95^{\mathrm{c}}$ & $-14.67 ;-1.23$ & & & & \\
\hline White-collar workers & & & & & $0.34^{\mathrm{b}}$ & $-0.03 ; 0.70$ \\
\hline \multicolumn{7}{|l|}{ Occupation status (ref: functionary) } \\
\hline Limited-term fulltime contract & & & & & -0.35 & $-0.85 ; 0.14$ \\
\hline Farmers/students/homemakers/unemployed/retired & & & 0.87 & $-0.37 ; 2.11$ & & \\
\hline Others & & & $2.63^{\mathrm{a}}$ & $0.70 ; 4.57$ & 0.39 & $-0.19 ; 0.97$ \\
\hline \multicolumn{7}{|l|}{ Satisfaction of amount of information about } \\
\hline COVID-I9 (ref: unsatisfied) & & & & & & \\
\hline Fairly satisfied & & & & & $-0.45^{\mathrm{a}}$ & $-0.74 ;-0.16$ \\
\hline Very satisfied & & & $0.76^{b}$ & $-0.06 ; 1.58$ & & \\
\hline Seeking information from television (Ref: no) & 4.39 & $-1.35 ; 10.13$ & $1.09^{c}$ & $0.16 ; 2.03$ & & \\
\hline $\begin{array}{l}\text { Hours per day spent to search for COVID-19 } \\
\text { information }\end{array}$ & -0.76 & $-1.76 ; 0.24$ & & & & \\
\hline
\end{tabular}

Notes: ${ }^{a} p<0.01 .{ }^{b} p<0.1 .{ }^{c} p<0.05$.

transmission than remaining groups. Using television as an information source was associated with greater awareness of COVID-19 transmission (Coef.: 1.09; 95\% CI: 0.16; 2.03).

Age groups and satisfaction with information sources were significantly associated with awareness of preventive behavioral practices. The 35-44 age group reported lower awareness of preventive practice domain scores (Coef.: -0.34 ; 95\% CI: $-0.67 ;-0.02$ ) compared to the under 25 age group. Lastly, respondents who were "fairly satisfied" with the source of information scored lower in the awareness of preventive practices domain (Coef: $-0.45 ; 95 \%$ CI: $-0.74 ;-0.16$ ) compared to those who responded "unsatisfied".

\section{Discussion}

The current study indicated that general population in Vietnam had strong awareness of local COVID-19 situation, transmission risks, and preventive behavioral practices. Factors found to be associated with residents' awareness of COVID-19 included age, family size, education level, satisfaction of the amount of information about COVID-19, and using television as an information source. These findings may provide valuable takeaways for COVID-19 response and 
risk communication including transmission risks, preventive behavioral practices, appearance of new variants, changes in COVID-19 transmission, and vaccine issues.

High levels of awareness provided evidence for the positive effects of early communication between Vietnamese government and residents. This outcome was completely similar to previous studies implemented in Chinese and Indian populations, ${ }^{35}$ and a survey among healthcare workers in Southern Vietnam towards the COVID-19 outbreak. ${ }^{36}$ In Vietnam, the government communication activities (the number of cases, recovered cases, and the epidemiological factors announced by official media channels including national television, government websites) contributed largely to the successful control of the outbreaks during their early stage. ${ }^{23}$ Previous studies suggested that early implementation of the risk communication strategies might provide accurate, sufficient, and timely awareness as well as guide appropriate preventive practice for residents, particularly in cases of infectious disease or epidemic. ${ }^{37,38}$

On the one hand, female participants were associated with a higher awareness of the local epidemic situation and transmission than males. This result was consistent with a study in China which reported that the majority of females had better awareness about COVID-19. ${ }^{39}$ Similarly, a study on knowledge, attitude, and perceptions toward COVID-19 implemented in Bangladesh also indicated that $80 \%$ of women had correct general knowledge of COVID-19 related to symptoms, causal agent, and treatment. ${ }^{40}$ By contrast, another study on awareness, attitude, and practice during COVID-19 in Saudi Arabia found that males were slightly more knowledgeable about the pandemic than females while females were more skilled at COVID-19 practices. $^{41}$ Generally, females were better aware of health-related issues and healthcare, especially infectious diseases and they also obtained more health information through informal sources such as family members, friends/workmates. ${ }^{42}$ Thus, the appropriate measures in public health promotion and interventions during the COVID-19 epidemic context should be considered based on the gender gap in health information behavior. We also observed a comparatively low awareness related to the COVID-19 situation in the locality among small family sizes (1-2 members) compared to families of 3-5 people or above 5 people. This finding corresponded to that of a previous study where the majority of families with more than 6 people had comparatively low level of awareness about COVID-19. ${ }^{43}$ Our study indicated that participants who obtained information about COVID-19 from television had higher awareness of transmission than those who received information from other sources. Television is a popular platform with direct impacts on the public's awareness and behavioral responses, and hence the implementation of prevention measures. ${ }^{23}$ Moreover, in Vietnam, recommendations on COVID-19 such as transmission ways, prevention means, health messages were widely disseminated through television and other media mass (the internet, newspapers, social network, etc.). ${ }^{44}$ These measures could adjust environmental stimulus and promote accurate awareness, knowledge, and practices. ${ }^{45,46}$

On the other hand, people between 35-44 years old had lower awareness of preventive behavioral practices on COVID-19 than other groups, including the group over 44 years old. Previous studies suggested that the awareness of the group over 44 years old was notably higher than others, as recorded in an investigation among health care workers in Vietnam during COVID-19 and MERS in Saudi Arabia. ${ }^{36,47}$ Such a big difference may be explained by the fact that a large proportion of older people suffered from chronic diseases and thus were usually more alert to emerging issues that threaten their health status and tended to take more precautions as the perceived risk increased. However, our findings indicated that the awareness of preventive behavioral practices within the 35-44 years old group was lower than the under-25 group. This contradictory outcome could be explained by the limitation of searching tools for official information on social platforms among this group, or the influence of fake news towards the accuracy of national response measures during the COVID-19 lockdown period. ${ }^{48}$ In the study, higher awareness of preventive behavioral practices for COVID-19 prevention was associated with lower satisfaction with information sources. However, a study in Uganda on the relationship between adherence of residents and satisfaction of received information sources quality indicated conflicting results as participants were more likely and willing to adhere to the preventive measures when COVID-19 information was supplied from healthcare workers, village leaders, and television. ${ }^{49}$ The recorded low levels of adherence to preventive measures among participants "fairly satisfied" with information sources might be explained by the disturbance of fake news leading to difficulties in screening information and reducing the effectiveness of communication strategies for pandemic control and prevention. ${ }^{23,44,48}$

In the first stage of the COVID-19 pandemic, most countries seemed to overlook the communication of risk, a typical example of which was the failure of Italy and Spain, where authorities' underestimation of the virus' spread has led to 
devastating explosions of COVID-19 cases and eventually the overflow of healthcare systems. Drawing on experience, the Vietnamese government agreed that improving awareness on COVID-19 for residents through communication has become an essential measure for effective control of the epidemic spread. ${ }^{48}$ Public announcement of the historical epidemiology report of confirmed cases had improved the resident's risk awareness, while early communication helped people understand the importance of their compliance with strict preventive measures, such as the 21-day home quarantine rule and immediate medical report after exposure, in reducing the pandemic burden for the country. ${ }^{50}$ Risk awareness played a crucial role, especially when vaccines, treatments, and screening tests were not sufficient nationwide. Early risk communication and early self-isolation remained vital practices as people may still test as "negative" in the early stages of the virus, and people infected may present as asymptomatic and spread the infection without knowing.

\section{Implications}

These current findings may contribute several insightful implications for scientific information sources regarding effectively controlling the COVID-19 spread in subsequent stages, as well as future infectious diseases. Firstly, the government should develop a well-planned and structured communication strategy between authorities and citizens including current status and preventive measures with special attention on marginalized people such as women, elderlies, large families, etc. Secondly, using social media for risk communication on COVID-19 can be helpful in reducing negative effects. Although information sources from social networking provided both negative and positive news for users, its indispensable role in seeking health-related information and social support was still mentioned in previous study. ${ }^{51}$ Therefore, government and policymakers should be planning to launch communication strategies on COVID-19 information in cyberspace, supplying correct information to prevent fear and crisis in society. ${ }^{52}$ Thirdly, triage systems and telephone-based screening should be promoted in the primary healthcare system. Establishing this system can prevent overloading the health system due to unnecessary referral of patients suspected of COVID-19 to hospital. Simultaneously, people also obtained correct medical information from healthcare workers. ${ }^{53}$ Lastly, comprehensive vaccine coverage should be provided for all residents by encouraging positive perceptions and beliefs regarding vaccination. Using mass media messages to improve knowledge towards COVID-19 immunization, especially highrisk subjects such as healthcare workers, policy workers, children, elderly, etc ..., to achieve herd immunity. ${ }^{54,55}$

\section{Limitations}

This study also had some limitations. Firstly, the study was carried out in a limited period of time, and thus were not able to cultivate a large sample size. Nonetheless, with a well-designed questionnaire and a quick response time, the study was able to address targeted issues and draw decisive conclusions. Secondly, the online survey model might lead to selection bias as only people with access to technology could be included. Thirdly, the data might not be generalized for Vietnam nationwide, as over $76 \%$ of participants resided in Northern. Despite its limitations, this study was able to achieve valuable insights into the levels of awareness among Vietnamese and offer resources for the prevention of COVID-19.

\section{Conclusion}

This study provides crucial insights into the awareness and risk communication effectiveness related to COVID-19 in Vietnam. Findings can help policymakers and authorities design or adapt current policies and interventions to best prepare our country against coronavirus. Government officials, health policy leaders, and other stakeholders should cooperate to increase awareness of local COVID-19 situation, transmission risks, and preventive behavioral practices. Their joined efforts should concentrate on developing the appropriate communication strategy, managing the quality of information resources, and developing the optimal preventive measures.

\section{Data Sharing Statement}

The data used to support the findings of this study are available from the corresponding author upon request. 


\section{Ethics Approval}

The research was ethically approved by the Review Committee at Institute for Preventive Medicine and Public Health, Hanoi Medical University according to the Decision 75/QD-YHDP\&YTCC dated 27 Mar 2020.

\section{Acknowledgments}

Research is supported by Vingroup Joint Stock Company (Vingroup JSC), Vingroup and supported by Vingroup Innovation Foundation (VINIF) under project code VINIF. 2020.COVID-19. DA03; NUS iHeathtech Other Operating Expenses (Grant No. R-722-000-004-731); and NUS Department of Psychological Medicine Other Operating Expenses (Grant No. R-177-000-100-001/R-177-000-003-001/R177000702733).

\section{Funding}

This study received funding from Vingroup Joint Stock Company (Vingroup JSC), Vingroup and was supported by Vingroup Innovation Foundation (VINIF) under project code VINIF. 2020.COVID-19. DA03. The funder was not involved in the study design, collection, analysis, interpretation of data, the writing of this article or the decision to submit it for publication. All authors declare no other competing interests. Publication fee for the manuscript was funded by the NUS Department of Psychological Medicine (R-177-000-100-001/R-177-000-003-001/R177000702733); and NUS iHeathtech Other Operating Expenses (R-722-000-004-731).

\section{Disclosure}

All authors report no conflicts of interest in this work.

\section{References}

1. Umakanthan S, Sahu P, Ranade AV, et al. Origin, transmission, diagnosis and management of coronavirus disease 2019 (COVID-19). Postgrad Med J. 2020;96(1142):753-758. doi:10.1136/postgradmedj-2020-138234

2. Azizi MR, Atlasi R, Ziapour A, Abbas J, Naemi R. Innovative human resource management strategies during the COVID-19 pandemic: a systematic narrative review approach. Heliyon. 2021;7(6):e07233. doi:10.1016/j.heliyon.2021.e07233

3. Aqeel M, Abbas J, Shuja KH, et al. The influence of illness perception, anxiety and depression disorders on students mental health during COVID-19 outbreak in Pakistan: a web-based cross-sectional survey. Int J Hum Rights Healthc. 2021. doi:10.1108/IJHRH-10-2020-0095

4. Li J, Wang D, Abbas J, Mubeen R. Tourists' health risk threats amid COVID-19 era: role of technology innovation, transformation, and recovery implications for sustainable tourism. Front Psychol. 2021;13:5280.

5. Umakanthan S, Chauhan A, Gupta MM, Sahu PK, Bukelo MM, Chattu VK. COVID-19 pandemic containment in the Caribbean Region: a review of case-management and public health strategies. AIMS Public Health. 2021;8(4):665. doi:10.3934/publichealth.2021053

6. World Health Organization. WHO Director-General's opening remarks at the mission briefing on COVID-19; 22 April, 2020 [Updated February 19, 2020]. Available from: https://www.who.int/dg/speeches/detail/who-director-general-s-opening-remarks-at-the-mission-briefing-on-covid-19. Accessed April 22, 2020.

7. World Health Organization. Coronavirus disease (COVID-19) outbreak situation; 1 May, 2020. [Updated April 30, 2020]. Available from: https:// www.who.int/emergencies/diseases/novel-coronavirus-2019. Accessed May 1, 2020.

8. Lai CC, Shih TP, Ko WC, Tang HJ, Hsueh PR. Severe acute respiratory syndrome coronavirus 2 (SARS-CoV-2) and coronavirus disease-2019 (COVID-19): the epidemic and the challenges. Int J Antimicrob Agents. 2020;55(3):105924. doi:10.1016/j.ijantimicag.2020.105924

9. Heymann DL, Shindo N. COVID-19: what is next for public health? Lancet. 2020;395(10224):542-545. doi:10.1016/S0140-6736(20)30374-3

10. Umakanthan S, Chattu VK, Ranade AV, Das D, Basavarajegowda A, Bukelo M. A rapid review of recent advances in diagnosis, treatment and vaccination for COVID-19. AIMS Public Health. 2021;8(1):137. doi:10.3934/publichealth.2021011

11. Su Z, McDonnell D, Li X, et al. COVID-19 vaccine donations-vaccine empathy or vaccine diplomacy? A narrative literature review. Vaccines. 2021;9(9):1024. doi:10.3390/vaccines9091024

12. Francis AI, Ghany S, Gilkes T, Umakanthan S. Review of COVID-19 vaccine subtypes, efficacy and geographical distributions. Postgrad Med J. 2021. doi:10.1136/postgradmedj-2021-140654

13. Umakanthan S, Patil S, Subramaniam N, Sharma R. COVID-19 vaccine hesitancy and resistance in India explored through a population-based longitudinal survey. Vaccines. 2021;9(10):1064. doi:10.3390/vaccines9101064

14. Mahase E. Covid-19: Where are We on Vaccines and Variants? British Medical Journal Publishing Group; 2021.

15. Hooker C, Leask J. Risk communication should be explicit about values. A perspective on early communication during COVID-19. J Bioeth Inq. 2020;17(4):581-589. doi:10.1007/s11673-020-10057-0

16. Shuja KH, Aqeel M, Khan EA, Abbas J. Letter to highlight the effects of isolation on elderly during COVID-19 outbreak. Int J Geriatr Psychiatry. 2020;35(12):1477-1478. doi:10.1002/gps.5423

17. Maqsood A, Abbas J, Rehman G, Mubeen R. The paradigm shift for educational system continuance in the advent of COVID-19 pandemic: mental health challenges and reflections. Curr Opin Behav Sci. 2021;2:100011. doi:10.1016/j.crbeha.2020.100011

18. Abbas J, Hussain T, Mubeen R, Wei Z, Raza S. Social media efficacy in crisis management: effectiveness of non-pharmaceutical interventions to manage the COVID-19 challenges. Front Psychiatry. 2021;12:1732. 
19. Vietnam Ministry of Health. "War" against COVID-19: start a new campaign. Ministry of Health of Vietnam; 23 April, 2020 [Updated March 8 , 2020]. Available from: https://moh.gov.vn/tin-tong-hop/-/asset_publisher/k206Q9qkZOqn/content/-cuoc-chien-chong-covid-19-bat-au-chien-dichmoi. Accessed April 23, 2020.

20. Prime Minister of Vietnam. Decision No 447/QD-TTg on announcing the nationwide outbreak of COVID-19. Vietnam PMo, editor; 2020.

21. University JH. Coronavirus COVID-19 global cases by the Center for Systems Science and Engineering (CSSE) at Johns Hopkins University. Available from: https://gisanddata.maps.arcgis.com/apps/dashboards/bda7594740fd40299423467b48e9ecf6. Accessed April 7, 2020.

22. Vietnam Ministry of Health. Information of COVID-19 epidemic. Ministry of Health of Vietnam; 1 May, 2020 [Updated April 30, 2020]. Available from: https://ncov.moh.gov.vn/. Accessed May 1, 2020.

23. La V-P, Pham T-H, Ho M-T, et al. Policy response, social media and science journalism for the sustainability of the public health system amid the COVID-19 outbreak: the Vietnam lessons. Sustainability. 2020;12(7):2931. doi:10.3390/su12072931

24. Tam LT, Ho HX, Nguyen DP, Elias A, Le ANH. Receptivity of governmental communication and its effectiveness during COVID-19 pandemic emergency in Vietnam: a qualitative study. Glob J Flex Syst Manag. 2021;22(1):45-64. doi:10.1007/s40171-021-00269-7

25. World Health Organization. Viet Nam COVID-19 Situation Report \#31; 28 February, 2021. Available from: https://www.who.int/vietnam/internalpublications-detail/covid-19-in-viet-nam-situation-report-31. Accessed March 5, 2021.

26. Centers for Disease Control Prevention. About variants of the virus that causes COVID-19. Centers for Disease Control Prevention; 5 March, 2021 [Updated February 12, 2021]. Available from: https://www.cdc.gov/coronavirus/2019-ncov/transmission/variant.html. Accessed March 5, 2021.

27. Hai V Vietnam to receive $5 \mathrm{mln}$ Covid-19 vaccine doses in February. VN Express International; 5 March, 2021. [Updated February 15, 2021]. Available from: https://e.vnexpress.net/news/news/vietnam-to-receive-5-mln-covid-19-vaccine-doses-in-february-4235752.html. Accessed March $5,2021$.

28. Akhtar N, Khan HU, Jan MA, Pratt CB, Jianfu M. Exploring the determinants of the China-Pakistan economic corridor and its impact on local communities. SAGE Open. 2021;11(4):21582440211057127. doi:10.1177/21582440211057127

29. Van Nguyen H, Khuong LQ, Nguyen AT, et al. Changes in, and predictors of, quality of life among patients with unstable angina after percutaneous coronary intervention. J Eval Clin Pract. 2020;27(2):325-332. doi:10.1111/jep.13416

30. Nguyen TH, Vu DC. Summary of the COVID-19 outbreak in Vietnam-Lessons and suggestions. Travel Med Infect Dis. $2020 ; 37: 101651$. doi:10.1016/j.tmaid.2020.101651

31. Trevisan M, Le LC, Le AV. The COVID-19 pandemic: a view from Vietnam. American Public Health Association; 2020.

32. Ivic S. Vietnam's Response to the COVID-19 Outbreak. Asian Bioeth Rev. 2020;12(3):341-347. doi:10.1007/s41649-020-00134-2

33. Symonds E. A practical application of SurveyMonkey as a remote usability-testing tool. Libr Hi Tech. 2011;29(3):436-445. doi:10.1108/ 07378831111174404

34. Wang C, Pan R, Wan X, et al. Immediate psychological responses and associated factors during the initial stage of the 2019 Coronavirus Disease (COVID-19) epidemic among the general population in China. Int J Environ Res Public Health. 2020;17(5). doi:10.3390/ijerph17051729

35. Chen N, Zhou M, Dong X, et al. Epidemiological and clinical characteristics of 99 cases of 2019 novel coronavirus pneumonia in Wuhan, China: a descriptive study. Lancet. 2020;395(10223):507-513. doi:10.1016/S0140-6736(20)30211-7

36. Huynh G, Nguyen TNH. Knowledge and attitude toward COVID-19 among healthcare workers at District 2 Hospital. Ho Chi Minh City; 2020.

37. Glik DC. Risk communication for public health emergencies. Annu Rev Public Health. 2007;28(1):33-54. doi:10.1146/annurev. publhealth.28.021406.144123

38. Rimal RN, Lapinski MK. Why health communication is important in public health. Bull World Health Organ. 2009;87(4):247-247a. doi:10.2471/ BLT.08.056713

39. Zhong B-L, Luo W, Li H-M, et al. Knowledge, attitudes, and practices towards COVID-19 among Chinese residents during the rapid rise period of the COVID-19 outbreak: a quick online cross-sectional survey. Int J Biol Sci. 2020;16(10):1745. doi:10.7150/ijbs.45221

40. Anwar S, Araf Y, Newaz khan A, et al. Women's knowledge, attitude, and perceptions toward COVID-19 in lower-middle-income countries: a representative cross-sectional study in Bangladesh. Front Public Health. 2020;8:721. doi:10.3389/fpubh.2020.571689

41. Alahdal H, Basingab F, Alotaibi R. An analytical study on the awareness, attitude and practice during the COVID-19 pandemic in Riyadh, Saudi Arabia. J Infect Public Health. 2020;13(10):1446-1452. doi:10.1016/j.jiph.2020.06.015

42. Ek S. Gender differences in health information behaviour: a Finnish population-based survey. Health Promot Int. 2015;30(3):736-745. doi:10.1093/ heapro/dat063

43. Gebretsadik D, Ahmed N, Kebede E, Gebremicheal S, Belete MA, Adane M. Knowledge, attitude, practice towards COVID-19 pandemic and its prevalence among hospital visitors at Ataye district hospital, Northeast Ethiopia. PLoS One. 2021;16(2):e0246154. doi:10.1371/journal. pone. 0246154

44. Ho HX, Nguyen DP, Elias A, Le ANH. Receptivity of governmental communication and its effectiveness during COVID-19 pandemic emergency in Vietnam: a qualitative study. Glob J Flex Syst Manag. 2021;22(1):45-64.

45. Rice RE, Atkin CK. Public communication campaigns: theoretical principles and practical applications. In: Media Effects. Routledge; 2009:452-484.

46. Rossmann C. Content effects: health campaign communication. In: The International Encyclopedia of Media Effects. 2017:1-11.

47. Albarrak AI, Mohammed R, Al Elayan A, et al. Middle East Respiratory Syndrome (MERS): comparing the knowledge, attitude and practices of different health care workers. J Infect Public Health. 2019;14:89-96.

48. Nguyen TTP, Nguyen DC, Nguyen ATT, et al. Fake news affecting the adherence of national response measures during the COVID-19 lockdown period: the experience of Vietnam. Opinion. Front Public Health. 2020;8(544). doi:10.3389/fpubh.2020.589872

49. Amodan BO, Bulage L, Katana E, et al. Level and determinants of adherence to COVID-19 preventive measures in the first stage of the outbreak in Uganda. Int J Environ Res Public Health. 2020;17(23):8810. doi:10.3390/ijerph17238810

50. Vietnam extends COVID-19 quarantine period to 21 days. Tuoi tre news; 19 May, 2021 [Updated May 06, 2021]. Available from: https:// tuoitrenews.vn/news/society/20210506/vietnam-extends-covid19-quarantine-period-to-21-days/60757.html. Accessed May 19, 2021.

51. Abbas J, Wang D, Su Z, Ziapour A. The role of social media in the advent of COVID-19 pandemic: crisis management, mental health challenges and implications. Risk Manag Healthc Policy. 2021;14:1917. doi:10.2147/RMHP.S284313

52. Yoosefi Lebni J, Abbas J, Moradi F, et al. How the COVID-19 pandemic effected economic, social, political, and cultural factors: a lesson from Iran. Int J Soc Psychiatry. 2021;67(3):298-300. doi:10.1177/0020764020939984 
53. NeJhaddadgar N, Ziapour A, Zakkipour G, Abbas J, Abolfathi M, Shabani M. Effectiveness of telephone-based screening and triage during COVID-19 outbreak in the promoted primary healthcare system: a case study in Ardabil Province, Iran. J Public Health. 2020;1-6. doi:10.1007/ s10389-020-01407-8

54. Huynh G, Nguyen HTN, Nguyen VT, Le pham A. Development and psychometric properties of the health belief scales toward COVID-19 vaccine in Ho Chi Minh City, Vietnam. Risk Manag Healthc Policy. 2021;14:2517. doi:10.2147/RMHP.S301645

55. Huynh G, Van Nguyen T, Nguyen DD, Lam QM, Pham TN, Nguyen HTN. Knowledge about COVID-19, beliefs and vaccination acceptance against COVID-19 among high-risk people in Ho Chi Minh City, Vietnam. Infect Drug Resist. 2021;14:1773. doi:10.2147/IDR.S308446

\section{Publish your work in this journal}

Risk Management and Healthcare Policy is an international, peer-reviewed, open access journal focusing on all aspects of public health, policy, and preventative measures to promote good health and improve morbidity and mortality in the population. The journal welcomes submitted papers covering original research, basic science, clinical \& epidemiological studies, reviews and evaluations, guidelines, expert opinion and commentary, case reports and extended reports. The manuscript management system is completely online and includes a very quick and fair peer-review system, which is all easy to use. Visit http://www.dovepress.com/testimonials.php to read real quotes from published authors.

Submit your manuscript here: https://www.dovepress.com/risk-management-and-healthcare-policy-journal 